\title{
The Response Modification Factor for Seismic Design of Integral Abutment Bridges
}

\author{
Shervin Maleki ${ }^{1}$, Alireza Siadat ${ }^{2}$ \\ 1. Sharif University of Technology, Tehran, Iran \\ 2. Dalhousie University, Nova Scotia, Canada \\ Email:smaleki@sharif.edu; siadat@dal.ca
}

Received: 24 March 2021; Accepted: 16 April 2021; Available online: 5 June 2021

\begin{abstract}
The response modification factor ( $\mathrm{R}$ factor) is a crucial parameter for calculating the design seismic forces applied to a bridge structure. This factor considers the nonlinear performance of bridges during strong ground motions. Conventional bridge structures rely on the substructure components to resist earthquake forces. Accordingly, there are $\mathrm{R}$ factors available in the design codes based on the type of bridge substructure system. Lateral load resisting system of Integral Abutment Bridges (IABs) in the longitudinal direction is more complex than ordinary bridges. It involves the contributions from soils behind the abutments and soil/structure interaction (SSI) in addition to existing rigid connection between the superstructure and abutments. There is no R factor available in any design code throughout the world for IABs in the longitudinal direction that considers all these parameters. In this research, the Federal Emergency Management Agency publication FEMA P695 methodology has been applied to estimate the $\mathrm{R}$ factor for IABs. It is found that 3.5 could be a safe and valid $\mathrm{R}$ factor in the longitudinal direction for seismic design of such bridges.
\end{abstract}

Keywords: Response modification factor; Integral abutment bridge; Seismic design; FEMA P695; Soil/Structure interaction.

\section{Introduction}

For many years, long span bridges were mainly designed and constructed as multiple simply supported spans until the moment distribution method was published in 1930 and facilitated the analysis of continuous spans and rigid frame bridges [1]. The integral abutment bridge (IAB) also benefits from continuity in a different way, namely between the superstructure and substructure, very similar to an arch bridge. This continuity eliminates the need for expansion joints at the abutments and due to extensive and costly problems associated with these joints, IABs are becoming a bridge system of choice throughout the world. The integration of abutment and deck speeds up the construction process of IABs and especially the accuracy required to install bearing devices. The maintenance costs of expansion joint devices are no longer of concern for IABs and less damage is expected to the structure as cars pass over the bridge. Also, in an earthquake, the unseating of the deck, which is a major problem in conventional bridges, is eliminated for IABs. Despite many advantages, secondary stresses due to thermal, shrinkage and creep are more of a concern for IABs. In general, the analysis of IABs is very complex and involves an indeterminate structure with soil/structure interaction (SSI) in its fullest form. The SSI should encompass soil/pile and soil/abutment and near/far field soil effects. Many researchers have worked on this complex SSI problem and suggested simplified analysis techniques for IABs under gravity, thermal and seismic actions [2-8].

The response modification factor ( $\mathrm{R}$ factor) is a crucial parameter for calculating the design earthquake forces of a bridge structure in the code specified linear seismic analysis procedures such as equivalent static load and response spectrum analyses [9]. This factor considers the nonlinear performance of bridges during strong ground motions. Conventional bridge structures rely on the substructure components to resist earthquake forces. Accordingly, there are R factors available in the design codes like AASHTO [9] based on the type of substructure system. The lateral force resisting system (LFRS) of IABs in the longitudinal direction is more complex than ordinary bridges. This is because of the lateral stiffness contribution from many components like the deck, abutments, piles, near field soils in the active and passive states, and soil inertia in the farfield and the interaction between them. There is no $\mathrm{R}$ factor available in any design code throughout the world for seismic design of IABs in the longitudinal direction that considers all the above parameters. This is mainly because an accurate analytical nonlinear analysis of these bridges under seismic actions is a hard task. In addition, the actual measured seismic responses of these bridges are only available in limited cases. 
Note that the transverse seismic response of IABs is very similar to conventional bridges with abutment walls resisting the seismic forces. Hence, in the transverse direction the available bridge design code prescribed R factors can be used with confidence.

This paper uses a nonlinear finite element (FE) analysis model that can capture the interaction between soils and all the structural components to analyze the IABs under gravity and seismic loading. In addition, the new FEMA P695 [10] methodology has been used to estimate the $\mathrm{R}$ factor for seismic design of IABs in the longitudinal direction.

\section{Literature review}

Seismic behavior of integral abutment bridges by considering soil-pile-abutment interaction has been the focus of research for the past two decades. Erhan and Dicleli [2] have shown that using loose sand around piles that are oriented to bend about their weak axes and abutment height less than $4 \mathrm{~m}$ without compaction of backfill results limited forces on abutment. In a parametric study of integral abutment bridges, Civjan et al. [3] have shown that IABs behavior is greatly affected by soil parameters and analysis procedure of structure. It was found that soil characteristics might change over time and after several cycles of loading and unloading of the bridge. Another study by Spyrakos et al. [4] have shown the importance of SSI and soil properties on the seismic behavior of IABs. Itani and Pekcan [5] have investigated the behavior of IABs with steel plate girders which led to the development of design recommendations. One of their most important findings was that the pile axis orientation is insignificant in the longitudinal behavior of IABs, because it is controlled by soil-abutment interaction. Another important finding was that the seismic performance of integral abutment bridges is better than the conventional seat type abutment bridges in terms of overall displacement. Also, a formulation for damping of IABs resulting to about $6 \%$ damping ratio for steel girder IABs in the longitudinal was recommended.

More recently, Mahjoubi and Maleki [6,7] have developed a new approach for considering embankment static and dynamic active and passive pressures on retaining walls and bridge abutments including IABs. As a result, an appropriate length of embankment finite element model length that minimizes the radiation damping effects has been found. In their study, about 4 times the abutment height for extension length of soil behind abutments was suggested. In their new approach in finite element modeling of IABs, soil pile structure interaction involving both near field and far field soil responses was considered. This method is practical for design purposes, resulting that nonlinearity of piles and soil are significant in analyzing of this system.

Experimental studies on collapse assessment of H-piles under abutment of IABs are very rare, however, Burdette et al. [8] have studied several steel piles driven into clay and noted that that H-piles have high levels of ductility while proposing 0.1 radians as the collapse margin for steel H-piles. Itani and Peckan [5] also have reported 0.1 radians as an appropriate collapse margin rotation for H-piles in their report.

\section{FEMA methodology in brief}

According to FEMA P695 [10], finding the right R factor for a structural system is a trial-and-error process. A trial $\mathrm{R}$ factor of 3.5 was initially selected for the IABs of this research. This value is justified because the longitudinal behavior of IABs is very similar to bents with vertical piles and AASHTO [9] recommends the use of 3.5 for these systems. In the next step, several so-called archetype structures should be developed and designed, such that they can cover all possible geometries and properties that IAB systems in practice might have (e.g., variety of abutment heights, embankment soil properties, etc.). In addition, the potential nonlinearities in the structural system under earthquake loading should be identified and considered in structural modeling and analysis of archetypes. After performing an incremental dynamic analysis (IDA) on each archetype using 22 prescribed far-field ground motions the values of collapse margin ratios (CMRs) are obtained. The ratio of the median collapse intensity to the maximum considered earthquake (MCE) intensity defines the CMR. Pushover analyses are also performed to determine the overstrength and ductility factor for each archetype. These are needed to calculate the spectral shape factors (SSFs). Then the adjusted collapse margin ratios (ACMRs) are calculated by multiplying CMRs and SSFs. The initial $\mathrm{R}$ factor is acceptable only if the individual and average ACMRs meet the safety criteria set in the standard, otherwise $\mathrm{R}$ factor is adjusted and the procedure is repeated.

The archetypes considered in this study are among the most used IABs in practice. They consist of single span and two span continuous bridges with varying span lengths, soil properties and abutment wall heights. In two-span continuous IABs, the superstructure was considered to be roller supported on the piers. The abutment wall heights were of two types: a $7 \mathrm{~m}$ wall type and a $3 \mathrm{~m}$ stub type. Two types of embankment soil types were considered: dense and loose, with properties as shown in Table 1. Three span lengths of 10, 20 and 30 meters were also considered. The slab-beam type superstructure of all archetypes was the same and is shown in Fig. 1-2. The abutment pile cap and piles are also depicted in Fig. 3. 

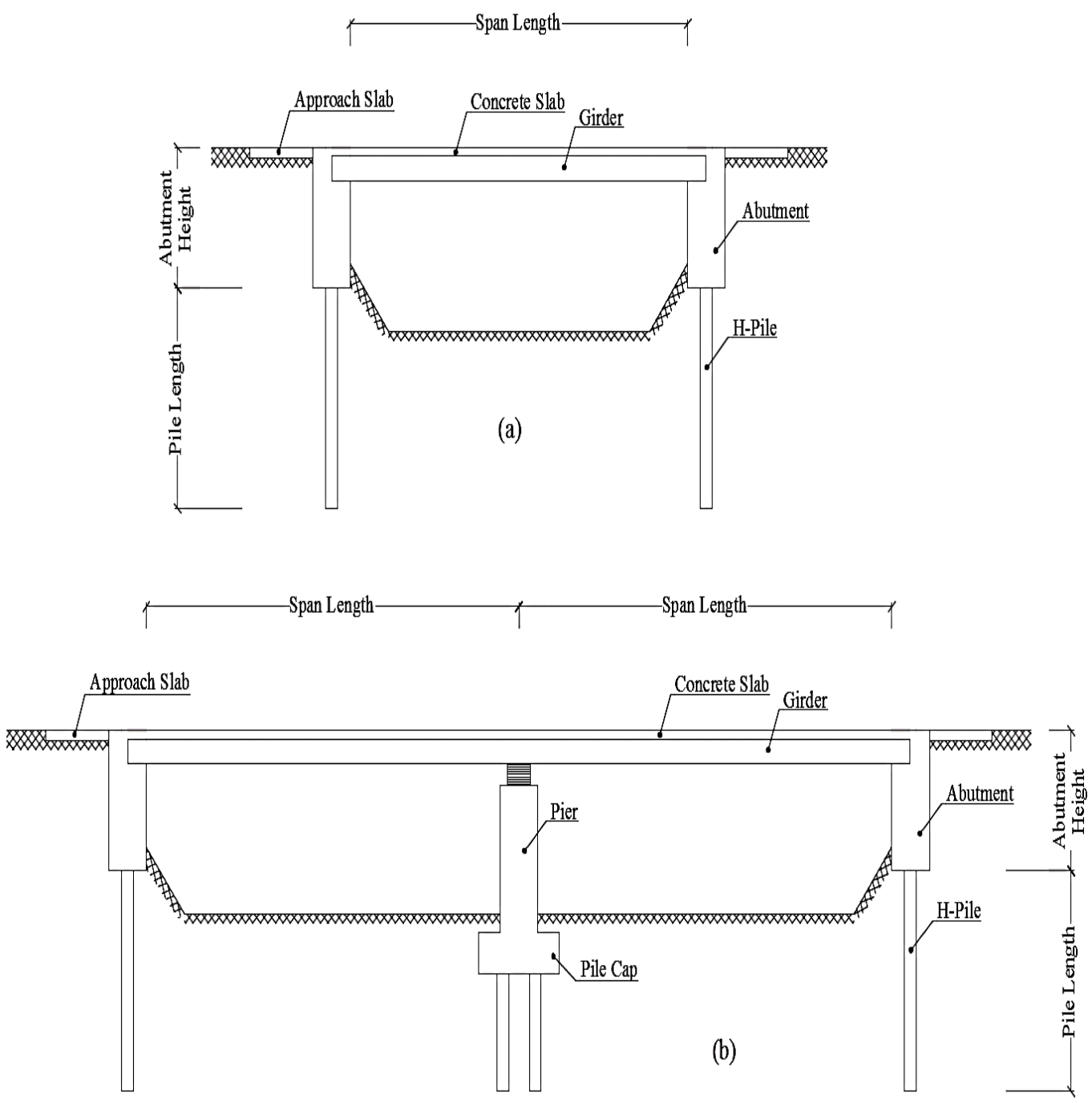

Fig. 1. Archetypes layout (a) Single span bridge (b) Multi-span bridge

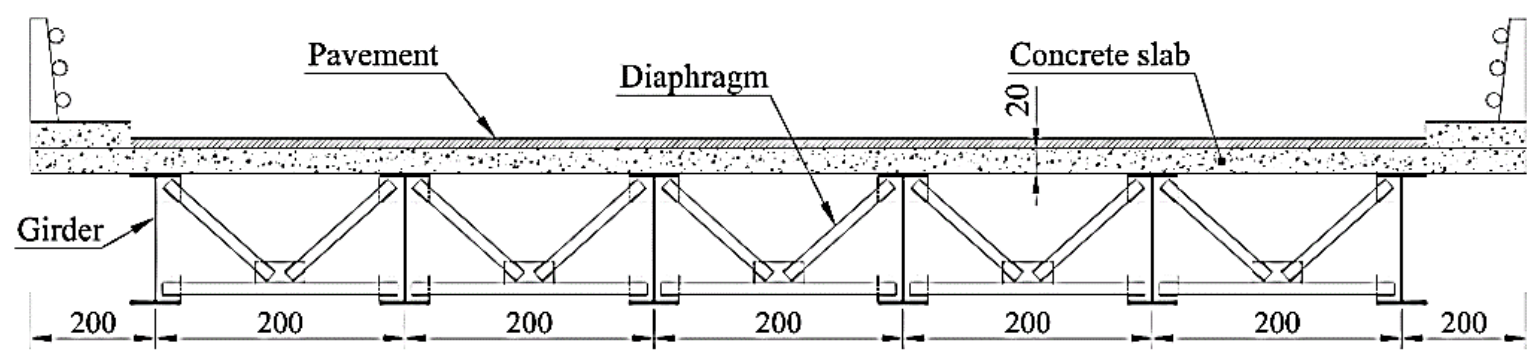

Fig. 2. Superstructure of all archetypes (dimensions in $\mathrm{cm}$ )

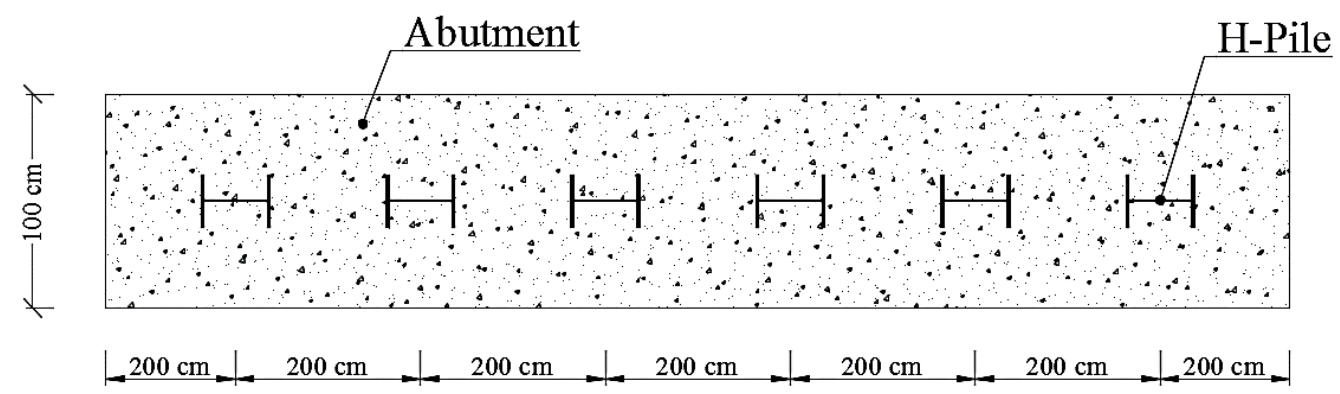

Fig. 3. Abutment and H-pile cross sections 
Table 1. Properties of dense and loose soil

\begin{tabular}{lll}
\hline Soil Properties & Dense Soil $(\mathrm{D})$ & Loose Soil $(\mathrm{L})$ \\
\hline Elasticity Modulus E $(\mathrm{MPa})$ & 80 & 15 \\
Poisson Ratio & 0.35 & 0.25 \\
Internal Friction Angle $\phi($ Degree $)$ & 38 & 30 \\
Minimum Unit Weight $\left(\mathrm{kN} / \mathrm{m}^{3}\right)$ & 17 & 14 \\
Maximum Unit Weight $\left(\mathrm{kN} / \mathrm{m}^{3}\right)$ & 22 & 18 \\
\hline
\end{tabular}

\section{Finite element modeling}

\subsection{Software and modeling}

Because of its special features and strong graphical user interface, SAP2000 [11] is used for modeling and analysis of archetypes. A single $2 \mathrm{~m}$ wide 2D FE model of each IAB containing one girder and one pile was considered for all analyses to account for the longitudinal behavior of structures. Since every $2 \mathrm{~m}$ slice of the bridge width is similar, this $2 \mathrm{D}$ modeling assumption would be a great time saving idea. Previous studies have shown that the longitudinal behavior of IABs using 3D and 2D modeling can yield similar results and 2D modeling is more efficient (Faraji et al. [12]).

\subsection{Deck modeling}

Deck consists of a $20 \mathrm{~cm}$ thick concrete slab made of normal weight concrete with $f_{c}^{\prime}=28 \mathrm{MPa}$. Steel girders and concrete slab were modeled using frame and shell elements, respectively. Both frame and shell elements were meshed such that they were constrained together at their junction to simulate the composite behavior of the girders. The steel girders used were American W sections of ST-37 grade with yield strength of $240 \mathrm{MPa}$. All girders were embedded inside the abutments for $50 \mathrm{~cm}$ in order to make rigid connections.

\subsection{Abutment and embankment modeling}

Abutments were modeled using shell elements made of normal weight concrete with $f_{c}^{\prime}=28 \mathrm{MPa}$. A fine grid mesh was used in modeling the abutments to increase accuracy and avoid unreasonable results. The modeling of the embankment soil behind the abutments followed the procedure described in Mahjoubi and Maleki [7] with some minor changes. Embankment modeling consisted of 2 parts: a multilinear elastic near-field soil springs capturing the static active/passive behavior of the soil and a far-field soil which is assumed to remain elastic in an earthquake but contributes to mass inertia (see Figs. 4-5). Membrane elastic shell elements were used for modeling the far-field soil to an extent (length) equal to 4 times the abutment height to eliminate radiation damping occurrence in the system due to earthquake wave propagation [7]. Note that, far-field soil can become nonlinear only in very severe earthquakes and in most cases remains elastic (Richards, et al. [13]).

In order to account for shear modulus variation of far-field-soil with depth, the soil was divided into sublayers of different mechanical properties. There are two assumptions for shear modulus variation of cohesionless soils with depth: linear and parabolic. Following Richards et al. [13] and assuming parabolic variation, the shear modulus for each sublayer is calculated as:

$$
G_{i}=G_{b} \sqrt{Z_{i} / H}
$$

where, $G_{i}=$ average shear modulus of sublayer $i, G_{b}=$ shear modulus at the bottom of embankment, $z_{i}=$ mean depth of sublayer $i, H=$ total depth of embankment.

The far-field-soil elements were restrained against horizontal and vertical translation at the bottom, where the earthquake time-history accelerations were also applied. The far end of far-field soil was restrained only against vertical translation. Far-field soil mass and stiffness will contribute to the inertia and stiffness of the total bridge structure when the gap elements are closed and the soil and structure are in contact.

The near-field soil behavior is modeled by a massless multilinear spring. The behavior is nonlinear but it is elastic. This means that the element loads and un-loads along the same curve, and no energy is dissipated. The elastic stiffness was calculated as follows:

$$
k_{i}=k_{s}^{Z} \times A_{i}
$$

where, $k_{s}^{z}=$ subgrade modulus at depth $z$ calculated by Eq. (3)

$$
k_{s}^{Z}=C G_{z} / H
$$




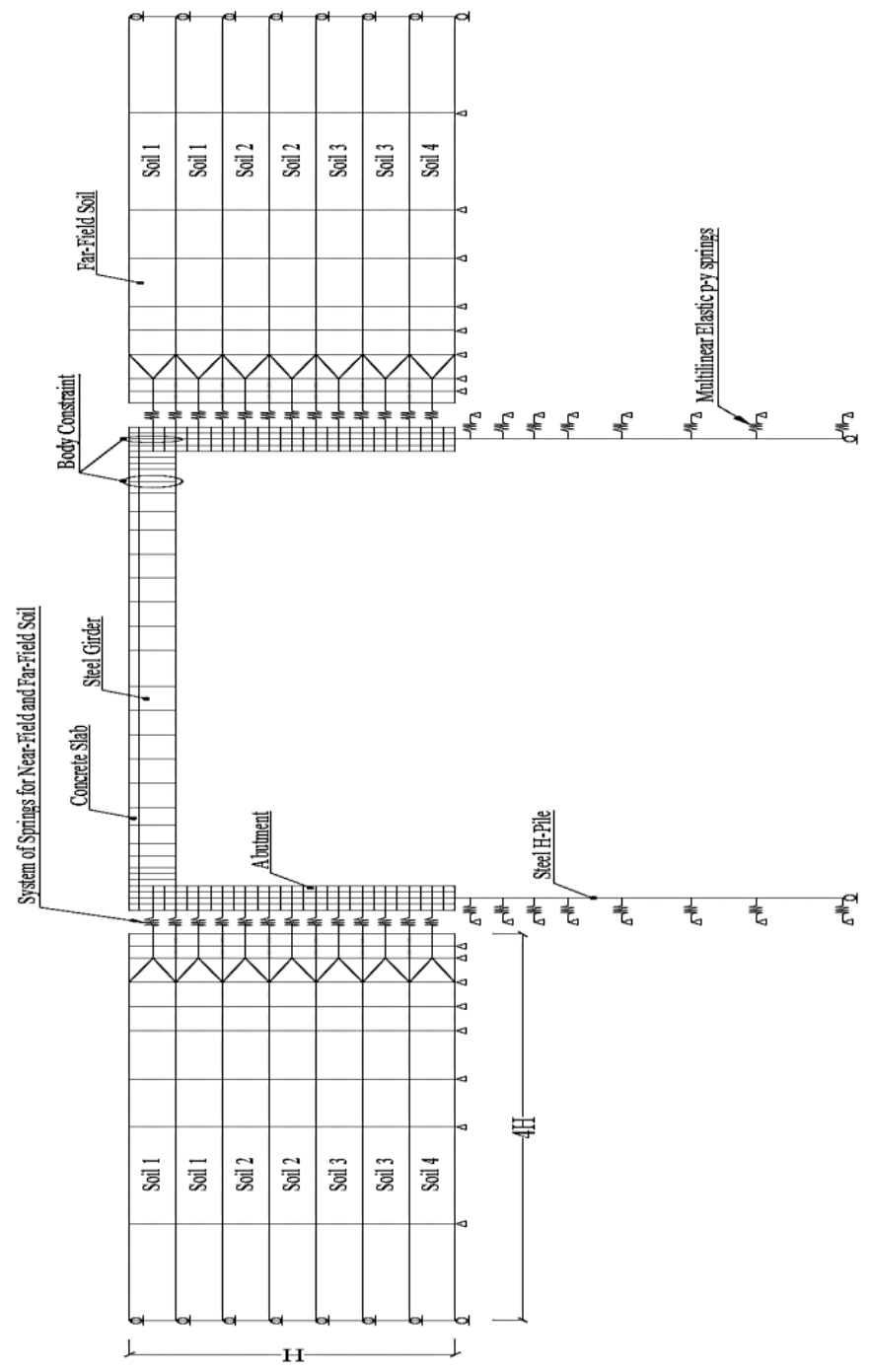

Fig. 4. Modeling layout of archetypes in the software

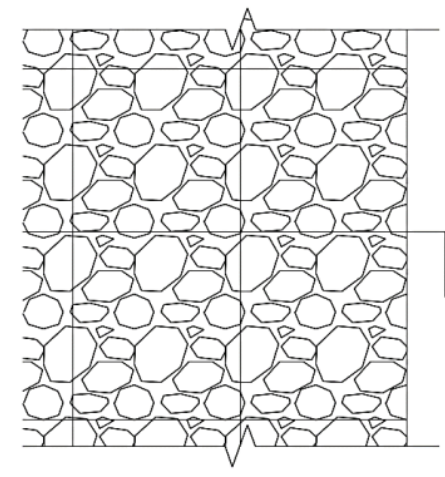

Far-Field Soil

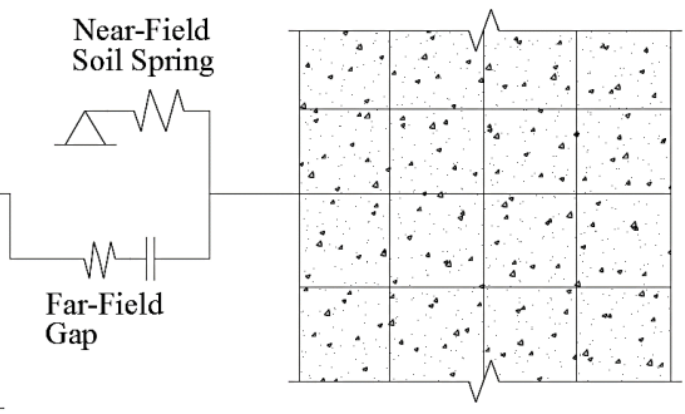

Abutment

Fig. 5. System of springs for near-field and far-field soils

In Eq. (3), $G_{z}=$ shear modulus at depth of $z, C=$ a shape factor of 1.35 based on Richards et al. [13]. $A_{i}=$ tributary area of spring calculated as:

$$
A_{i}=B \times d
$$


where, $B=$ model width, $d=$ tributary height of spring, which is equal to distance between springs.

There are upper (passive) and lower (active) limits for these springs as mathematically shown in Eq. (5). The exerted soil forces on the wall is always within these limits:

$$
P_{a}=k_{a} \cdot \gamma_{i} \cdot z_{i} \cdot A_{i} \leq F_{i}=k_{i} \cdot \delta_{i} \leq P_{p}=k_{p} \cdot \gamma_{i} \cdot z_{i} \cdot A
$$

in which, $\gamma_{i}$ is soil unit weight at depth, $z_{i}$ which is calculated by assuming linear variation of unit weight in depth. $\delta_{i}$ is abutment displacement or spring deformation at depth $z_{i} . k_{a}$ is active and $k_{p}$ as passive earth pressure coefficients computed based on Rankine formulation for simplicity:

$$
k_{a}=\frac{1-\sin \phi}{1+\sin \phi} ; k_{p}=\frac{1+\sin \phi}{1-\sin \phi}
$$

where $\phi$ is the soil internal friction angle.

General force-displacement relationship for near-field soil spring model is shown in Fig. 6.

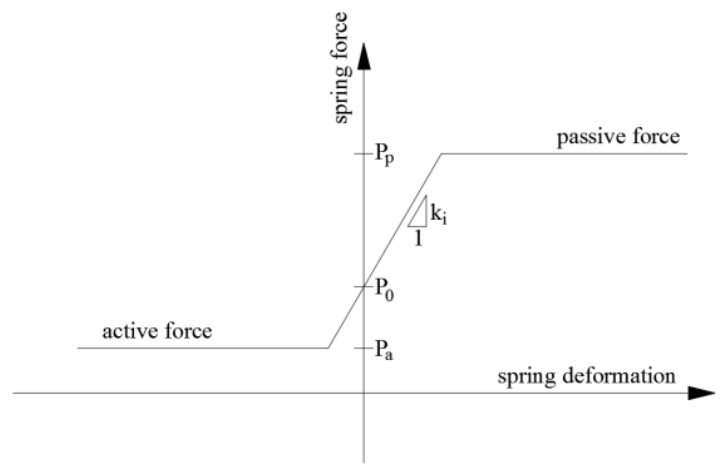

Fig. 6. Near field soil behavior

\subsection{Pile and adjacent soil modeling}

The $7 \mathrm{~m}$ length piles were modeled using frame elements of steel $\mathrm{H}$ sections. Multilinear elastic springs with force-deformation relationship based on API p-y curves [14] were developed and modeled along pile length for accounting the actual soil pressure acting on piles. An example of $\mathrm{p}$-y curve assigned to a multilinear elastic link element in SAP2000 is shown in Fig. 7. The pile bottom was restrained against vertical displacement in all models. In this research, the source of potential nonlinearity is considered to be in piles. Thus, fiber P-M-M hinges was defined continuously along the upper $3 \mathrm{~m}$ of piles where the occurrence of plastic hinges was expected.

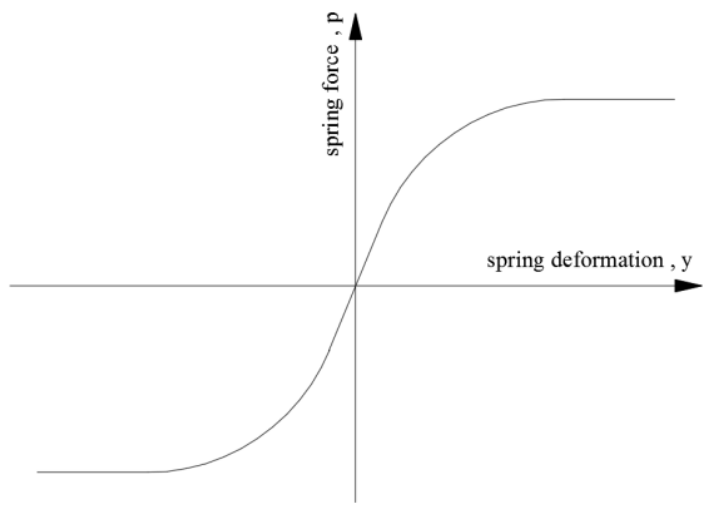

Fig. 7. p-y curve concept used in multilinear elastic springs along pile length

\subsection{Analysis}

The piles in IABs experience large displacements. Therefore, P-Delta effects must be considered in the analyses of all archetypes. Damping ratio of 5\% is a common value for analysis of bridge structures and is considered to be conservative to use in this study. 


\section{Design of Archetypes}

Archetypes were first designed based on AASHTO LRFD [9] specifications for gravity, thermal and seismic loading. SAP2000 was used for analysis and calculation of demands in structural elements. The details of structural modeling were discussed in the previous sections. Seismic demands were calculated based on the assumption that the bridges were located in China Town, Los Angeles, California. Thus, site class D was assigned and $S_{s}$ and $S_{l}$ values of 1.664 and 0.5576 were used, respectively. The PGA for the site was 0.7064 . The design basis earthquake (DBE) and MCE spectra are shown in Fig. 8. Temperature loading was considered in calculating demands according to moderate climate conditions. The designed girder sections were chosen from American wide flange sections and piles were selected from HP sections. The designed IAB archetypes properties are shown in Table 2.

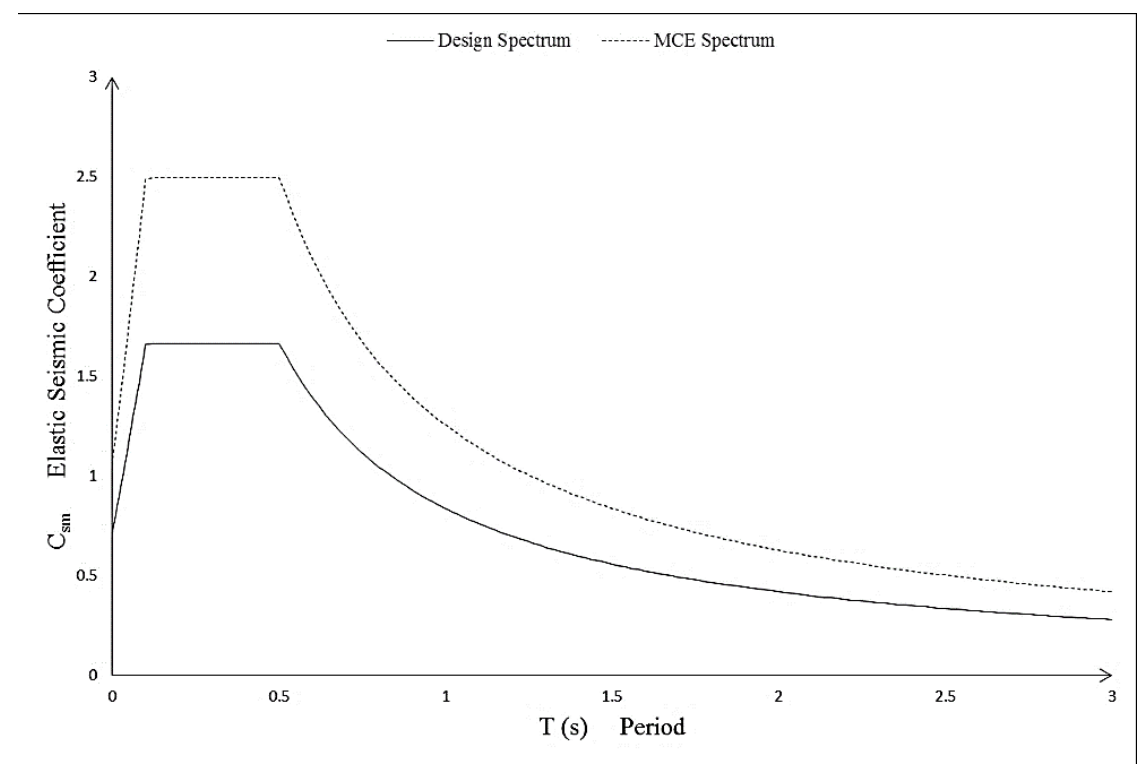

Fig. 8. DBE and MCE earthquake spectra

Table 2. Designed archetypes properties

\begin{tabular}{|c|c|c|c|c|c|c|}
\hline Model ID & Abutment Type & $\begin{array}{l}\text { Soil } \\
\text { Type }\end{array}$ & $\begin{array}{c}\text { Span Length } \\
(\mathrm{m})\end{array}$ & No. of Spans & Pile Section & Girder Section \\
\hline W10D1 & \multirow{12}{*}{ Wall type } & \multirow{6}{*}{ Dense } & \multirow{2}{*}{10} & 1 & HP12X63 & W24X68 \\
\hline W10D2 & & & & 2 & HP13X60 & W24X68 \\
\hline W20D1 & & & \multirow{2}{*}{20} & 1 & HP12X53 & W40X167 \\
\hline W20D2 & & & & 2 & HP12X63 & $\mathrm{W} 44 \mathrm{X} 262$ \\
\hline W30D1 & & & \multirow{2}{*}{30} & 1 & HP12X63 & W44X262 \\
\hline W30D2 & & & & 2 & HP13X87 & $\mathrm{W} 44 \mathrm{X} 262$ \\
\hline W10L1 & & \multirow{6}{*}{ Loose } & \multirow{2}{*}{10} & 1 & HP12X63 & W24X76 \\
\hline W10L2 & & & & 2 & HP13X73 & W24X76 \\
\hline W20L1 & & & \multirow{2}{*}{20} & 1 & HP13X60 & W40X183 \\
\hline W20L2 & & & & 2 & HP13X73 & W40X183 \\
\hline W30L1 & & & \multirow{2}{*}{30} & 1 & HP13X73 & W44X262 \\
\hline W30L2 & & & & 2 & HP13X73 & $\mathrm{W} 44 \mathrm{X} 262$ \\
\hline S10D1 & \multirow{12}{*}{ Stub type } & \multirow{6}{*}{ Dense } & \multirow{2}{*}{10} & 1 & HP12X53 & W24X84 \\
\hline S10D2 & & & & 2 & HP12X53 & W24X84 \\
\hline S20D1 & & & \multirow{2}{*}{20} & 1 & HP13X73 & W40X167 \\
\hline S20D2 & & & & 2 & HP13X73 & W40X167 \\
\hline S30D1 & & & \multirow{2}{*}{30} & 1 & HP14X117 & W40X262 \\
\hline S30D2 & & & & 2 & HP16X121 & $\mathrm{W} 44 \mathrm{X} 262$ \\
\hline S10L1 & & \multirow{6}{*}{ Loose } & \multirow{2}{*}{10} & 1 & HP12X53 & W24X76 \\
\hline S10L2 & & & & 2 & HP13X60 & W24X76 \\
\hline S20L1 & & & \multirow{2}{*}{20} & 1 & HP14X89 & W40X149 \\
\hline S20L2 & & & & 2 & HP13X73 & W40X149 \\
\hline S30L1 & & & \multirow{2}{*}{30} & 1 & HP16X141 & W44X262 \\
\hline S30L2 & & & & 2 & HP16X121 & W44X262 \\
\hline
\end{tabular}




\subsection{Input ground motions}

Ground motions are selected according to FEMA-P695 specifications [10]. The methodology provides 22 pairs of preselected far-field record set from sites farther than $10 \mathrm{~km}$ from fault rupture (see Table 3). The record set does not include the vertical component of ground motions. In addition, since the analysis models were 2D, only the horizontal component with higher PGA was used in nonlinear analyses. There are two steps of scaling in this methodology. First, the set of ground motions are normalized with respect to the median PGV of record set. Thus, each ground motion record should be multiplied by the factor $N M_{i}$ calculated as:

$$
N M_{i}=\frac{\operatorname{Median}\left(P G V_{i}\right)}{P G V_{i}}
$$

Table 3. Far-Field ground motions [10]

\begin{tabular}{|c|c|c|c|c|}
\hline ID & $\begin{array}{l}\text { Name } \\
\text { Station }\end{array}$ & Year & Magnitude & Component $\left(^{\circ}\right)$ \\
\hline 1 & $\begin{array}{l}\text { Northridge } \\
\text { Beverly Hills - Mulhol }\end{array}$ & 1994 & 6.7 & MUL279 \\
\hline 2 & $\begin{array}{l}\text { Northridge } \\
\text { Canyon Country - WLC }\end{array}$ & 1994 & 6.7 & LOS270 \\
\hline 3 & $\begin{array}{l}\text { Duzce, Turkey } \\
\text { Bolu }\end{array}$ & 1999 & 7.1 & BOL090 \\
\hline 4 & $\begin{array}{l}\text { Hector Mine } \\
\text { Hector }\end{array}$ & 1999 & 7.1 & HEC090 \\
\hline 5 & $\begin{array}{l}\text { Imperial Valley } \\
\text { Delta }\end{array}$ & 1979 & 6.5 & DLT352 \\
\hline 6 & $\begin{array}{l}\text { Imperial Valley } \\
\text { El Centro Array \#11 }\end{array}$ & 1979 & 6.5 & E11230 \\
\hline 7 & $\begin{array}{l}\text { Kobe, Japan } \\
\text { Nishi-Akashi }\end{array}$ & 1995 & 6.9 & NIS090 \\
\hline 8 & $\begin{array}{l}\text { Kobe, Japan } \\
\text { Shin-Osaka }\end{array}$ & 1995 & 6.9 & SHI090 \\
\hline 9 & $\begin{array}{l}\text { Kocaeli, Turkey } \\
\text { Duzce }\end{array}$ & 1999 & 7.5 & DZC270 \\
\hline 10 & $\begin{array}{l}\text { Kocaeli, Turkey } \\
\text { Arcelik }\end{array}$ & 1999 & 7.5 & ARE000 \\
\hline 11 & $\begin{array}{l}\text { Landers } \\
\text { Yermo Fire Station }\end{array}$ & 1992 & 7.3 & YER270 \\
\hline 12 & $\begin{array}{l}\text { Landers } \\
\text { Coolwater }\end{array}$ & 1992 & 7.3 & CLW-TR \\
\hline 13 & $\begin{array}{l}\text { Loma Prieta } \\
\text { Capitola }\end{array}$ & 1989 & 6.9 & CAP000 \\
\hline 14 & $\begin{array}{l}\text { Loma Prieta } \\
\text { Gilroy Array \#3 }\end{array}$ & 1989 & 6.9 & G03000 \\
\hline 15 & $\begin{array}{l}\text { Manjil, Iran } \\
\text { Abbar }\end{array}$ & 1990 & 7.4 & ABBAR--L \\
\hline 16 & $\begin{array}{l}\text { Superstition Hills } \\
\text { El Centro Imp. Co. }\end{array}$ & 1987 & 6.5 & ICC000 \\
\hline 17 & $\begin{array}{l}\text { Superstition Hills } \\
\text { Poe Road (temp) }\end{array}$ & 1987 & 6.5 & POE270 \\
\hline 18 & $\begin{array}{l}\text { Cape Mendocino } \\
\text { Rio Dell Overpass }\end{array}$ & 1992 & 7.0 & $*$ \\
\hline 19 & $\begin{array}{l}\text { Chi-Chi, Taiwan } \\
\text { CHY101 }\end{array}$ & 1999 & 7.6 & $\mathrm{~N}$ \\
\hline 20 & $\begin{array}{l}\text { Chi-Chi, Taiwan } \\
\text { TCU045 }\end{array}$ & 1999 & 7.6 & $\mathrm{~N}$ \\
\hline 21 & $\begin{array}{l}\text { San Fernando } \\
\text { LA - Hollywood Stor }\end{array}$ & 1971 & 6.6 & PEL090 \\
\hline 22 & $\begin{array}{l}\text { Friuli, Italy } \\
\text { Tolmezo }\end{array}$ & 1976 & 6.5 & TMZ000 \\
\hline
\end{tabular}

*This record has been removed from PEER database. 
where, Median $\left(P G V_{i}\right)$ is the median of peak ground velocities of all ground motions and $P G V_{i}$ is the peak ground velocity of each ground motion record. This phase is to eliminate unwarranted variability among the records because of the inherent variances in distance to source, source type, event magnitude and site conditions without removing the entire record-to-record variability. In the second scaling phase, normalized ground motions should be collectively scaled to a specified ground motion intensity in a way that the median spectral acceleration of record set matches the spectral acceleration at the fundamental period of $T$ of analyzed archetype [10]. Fig. 9 shows a sample of the scaled spectrum.

\subsection{Calculation of median collapse intensity and CMR}

While incremental dynamic analysis (IDA) is used to show the collapse assessment process, methodology needs the median collapse intensity $\left(\hat{S}_{C T}\right)$ calculated with fewer nonlinear analyses than is necessary to develop the full IDA curve. $\hat{S}_{C T}$ could be obtained by scaling all the records to MCE intensity $\left(S_{M T}\right)$ by raising the intensity of scaled records until over one half of ground motion records cause collapse. The least intensity at which one half of records cause collapse is the median collapse intensity. MCE intensity is gained from the response spectrum of MCE ground motions at $T$ (fundamental period). The ratio between MCE intensity and median collapse intensity is the collapse margin ratio (CMR) [10].

$$
C M R=\frac{\hat{S}_{C T}}{S_{M T}}
$$

\subsection{Pile collapse criteria}

As mentioned before, very few experimental studies covering the collapse of steel H-pile sections about their weak axes have been performed and can not be generalized for all types of steel H-pile sections. As a safe and reasonable assumption, it is considered in this research that piles behavior and performance levels can be measured using ASCE 41-13 [15] criteria for steel columns in moment frames. This is not far from reality, because the piles under cyclic loading in their upper portions where plastic hinges develop tend to loosen the adjacent soil support. Thus, it is conservative to assume a behavior like steel columns.

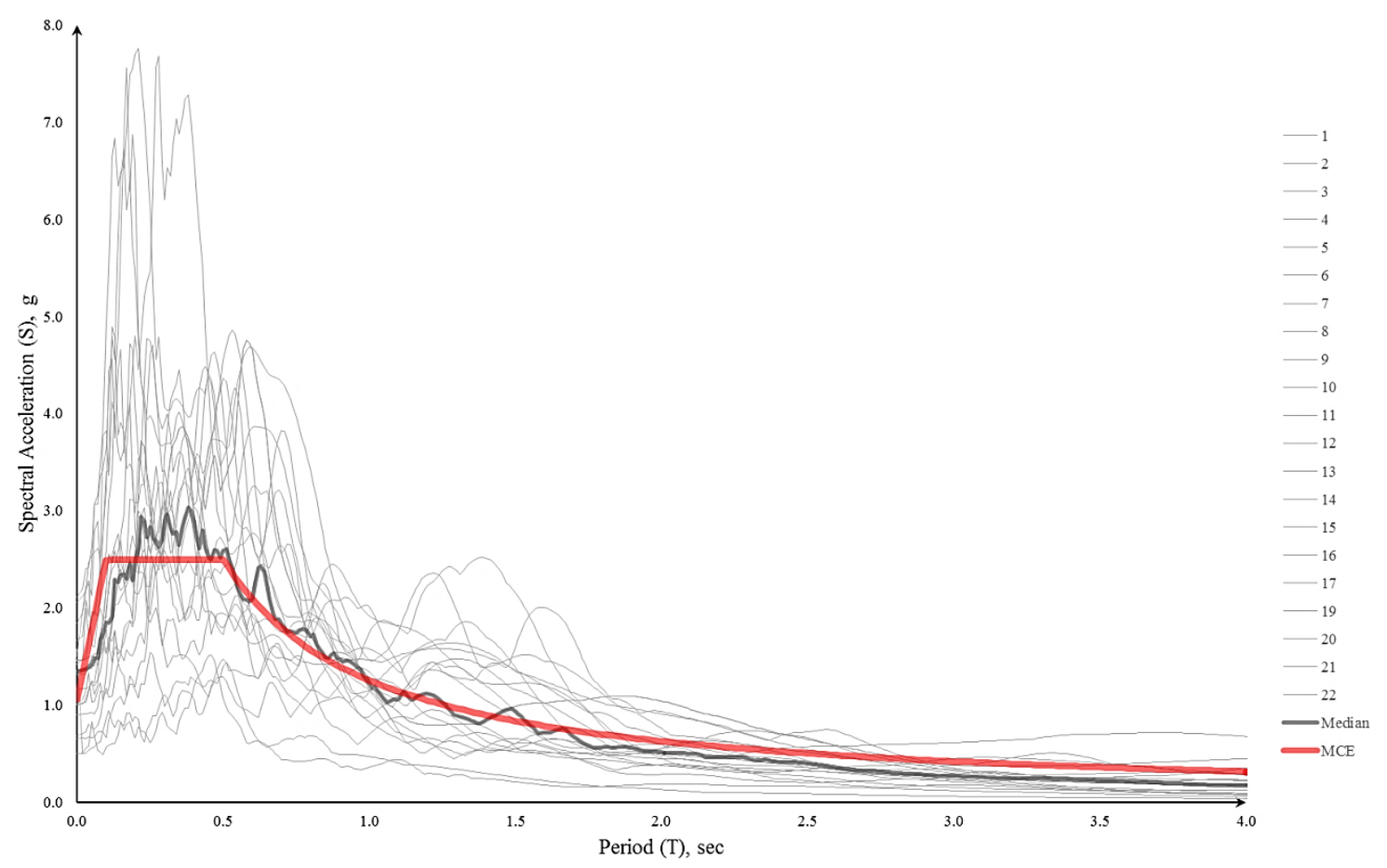

Fig. 9. Ground motions spectra scaled to MCE for W20D1 with T=0.20 s

\subsection{Calculation of spectral shape factor, SSF, and ACMR}

According to Baker and Cornell [16], the rare ground motions in the western United States corresponded to MCE have a distinct spectral shape which are different from the spectral shape of design spectrum applied for the structural design in ASCE/SEI 7. 
To remove this conservative bias, a simplified spectral shape factor, SSF, which depends on the fundamental period $(\mathrm{T})$ and period based ductility $\left(\mu_{\mathrm{T}},\right)$ are used to adjust collapse margin ratios as [10]:

$A C M R=S S F \times C M R$

$\mathrm{SSF}$ is the spectral shape factor and is calculated by Eq. (12).

\subsection{Fundamental period of archetypes}

To obtain the fundamental period of archetypes, modal analyses were performed and the period of predominant longitudinal mode of vibration (with the highest mass contribution) was selected as the fundamental period and is reported in Table 4.

Table 4. Ground motion and structural behavior parameters

\begin{tabular}{ccccccccc}
\hline ID & $\mathrm{T}(\mathrm{s})$ & $\mu$ & $\bar{\varepsilon}(T)_{\text {records }}$ & $\bar{\varepsilon}_{0}$ & $\beta_{1}$ & $\mathrm{SSF}$ & CMR & ACMR \\
\hline W10D1 & 0.19 & 1.60 & 0.60 & 1.50 & 0.11 & 1.11 & 2.15 & 2.38 \\
W10D2 & 0.24 & 2.20 & 0.60 & 1.50 & 0.15 & 1.15 & 2.03 & 2.33 \\
W20D1 & 0.20 & 1.50 & 0.60 & 1.50 & 0.10 & 1.10 & 1.80 & 1.98 \\
W20D2 & 0.29 & 1.50 & 0.60 & 1.50 & 0.10 & 1.10 & 1.73 & 1.90 \\
W30D1 & 0.23 & 1.60 & 0.60 & 1.50 & 0.11 & 1.11 & 2.11 & 2.34 \\
W30D2 & 0.38 & 3.20 & 0.60 & 1.50 & 0.19 & 1.19 & 1.90 & 2.26 \\
W10L1 & 0.30 & 1.90 & 0.60 & 1.50 & 0.13 & 1.13 & 1.64 & 1.85 \\
W10L2 & 0.38 & 2.90 & 0.60 & 1.50 & 0.18 & 1.18 & 1.61 & 1.90 \\
W20L1 & 0.30 & 2.00 & 0.60 & 1.50 & 0.14 & 1.13 & 1.57 & 1.78 \\
W20L2 & 0.43 & 1.20 & 0.60 & 1.50 & 0.07 & 1.07 & 2.10 & 2.24 \\
W30L1 & 0.33 & 1.60 & 0.60 & 1.50 & 0.11 & 1.11 & 1.70 & 1.88 \\
W30L2 & 0.54 & 1.40 & 0.58 & 1.50 & 0.10 & 1.09 & 1.50 & 1.64 \\
S10D1 & 0.11 & 1.70 & 0.60 & 1.50 & 0.12 & 1.11 & 2.95 & 3.29 \\
S10D2 & 0.16 & 1.50 & 0.60 & 1.50 & 0.10 & 1.10 & 3.08 & 3.38 \\
S20D1 & 0.12 & 2.10 & 0.60 & 1.50 & 0.15 & 1.14 & 3.29 & 3.75 \\
S20D2 & 0.22 & 1.60 & 0.60 & 1.50 & 0.11 & 1.11 & 3.36 & 3.72 \\
S30D1 & 0.14 & 2.00 & 0.60 & 1.50 & 0.14 & 1.13 & 3.39 & 3.85 \\
S30D2 & 0.35 & 1.70 & 0.60 & 1.50 & 0.12 & 1.11 & 3.11 & 3.47 \\
S10L1 & 0.17 & 2.30 & 0.60 & 1.50 & 0.16 & 1.15 & 2.51 & 2.89 \\
S10L2 & 0.23 & 2.10 & 0.60 & 1.50 & 0.15 & 1.14 & 2.62 & 2.99 \\
S20L1 & 0.18 & 2.60 & 0.60 & 1.50 & 0.17 & 1.17 & 2.82 & 3.29 \\
S20L2 & 0.29 & 2.10 & 0.60 & 1.50 & 0.15 & 1.14 & 1.90 & 2.17 \\
S30L1 & 0.20 & 3.60 & 0.60 & 1.50 & 0.21 & 1.21 & 2.48 & 2.99 \\
S30L2 & 0.39 & 2.50 & 0.60 & 1.50 & 0.17 & 1.16 & 1.99 & 2.31 \\
\hline & & & & & & & &
\end{tabular}

\subsection{Ductility, $\mu$}

Nonlinear static analyses were conducted on archetypes in order to calculate their ductility. Control node for pushover analyses was chosen at the middle of the deck. Since the source of nonlinearity is located at the top part of piles and there is no other source of nonlinearity in the models, then the structure would not face instability or large loss of stiffness after formation of plastic hinges. In this case, ductility was calculated based on piles pushover diagram as:

$$
\mu=\frac{\Delta_{u}^{\text {Collapse }}}{\Delta_{y}^{e f f, y i e l d}}
$$

in which, $\Delta_{u}^{\text {Collapse }}$ is the control node displacement corresponding to the first collapse plastic rotation occurrence in piles and $\Delta_{y}^{e f f, y i e l d}$ is displacement of control node corresponding to first yield rotation in piles. Calculated ductility values are listed in Table 4.

\subsection{Epsilon parameter}

The epsilon $(\varepsilon)$ ground motion parameter is defined as an indicator of spectral shape. This parameter is a difference measurement between the spectral acceleration of a record and the mean of a ground motion prediction equation at a given period [16]. With regards to the equation proposed for Far-Field ground motions set: 


$$
\bar{\varepsilon}(T)_{\text {records }}=(0.6)(1.5-T) \leq 0.6
$$

where $T$ is the fundamental free vibration period of structure. Value of $\bar{\varepsilon}(T)_{\text {records }}$ is calculated for each archetype and reported in Table 4.

\section{$5.8 \beta_{1}$ and SSF parameters}

SSF factor is calculated as:

$$
S S F=\exp \left[\beta_{1}\left(\bar{\varepsilon}_{0}(T)-\bar{\varepsilon}(T)_{\text {records }}\right)\right]
$$

where, $\beta_{1}$ is based on the building inelastic deformation capacity and $\bar{\varepsilon}_{0}$ is based on SDC equivalent to 1.0 for SDC B/C, 1.5 for SDC D, and 1.2 for SDC E. In this research, $\bar{\varepsilon}_{0}$ is considered to be 1.50 , and $\beta_{1}$ is applied to quantify how drastically the spectral shape $(\varepsilon)$ impacts the collapse capacity as below:

$$
\beta_{1}=(0.14)(\mu-1)^{0.42} \leq 0.32
$$

\subsection{Acceptable values of $A C M R$}

Acceptable values of $A C M R$ are based on total system collapse uncertainty $\left(\beta_{T O T}\right)$ and on the established variables of acceptable collapse probabilities assumed that the distribution of collapse level spectral intensities is lognormal with a median value $\left(\hat{S}_{C T}\right)$ and a lognormal standard deviation that is equivalent to total system collapse uncertainty $\left(\beta_{\text {TOT }}\right)$.

$$
A C M R_{\text {acceptable }}=\frac{1}{e^{\left(\phi^{-1}\left(P_{\text {Collapse }}\right) \times \beta_{T O T}\right)}}
$$

Acceptable performance is achieved when [10]:

Average $A C M R$ value for all archetypes in a performance group exceeds $A C M R_{10 \%}$ :

$$
\overline{A C M R}_{i} \geq A C M R_{10 \%}=2.30
$$

the individual variable of $A C M R$ for every index archetype exceeds $A C M R_{20 \%}$ :

$$
A C M R_{i} \geq A C M R_{20 \%}=1.73
$$

It means that the collapse probability for MCE ground motions is about $10 \%$, or lower averagely during the archetypes group and the collapse probability for MCE ground motions is about $20 \%$ or lower for all index archetype into the group.

\subsection{Total system collapse uncertainty}

Majority of uncertainty sources are contributed to variability. Larger variability in the overall collapse prediction necessitates larger collapse margins to confined the collapse probability to a confirmed level at MCE intensity. Evaluating all the significant uncertainty sources in collapse response and for incorporating their impact in the collapse assessment procedure is important. The following uncertainty sources are taken in the collapse assessment procedure:

1) Record-to-Record Uncertainty (RTR) is because of the variability of index archetypes response to altered ground motion records as below [10]:

$$
\beta_{R T R}=0.1+0.1 \mu_{T} \leq 0.4
$$

That will be $\beta_{R T R}=0.30$ on average of all archetypes.

2) Design Requirements Uncertainty (DR) is associated to the robustness and completeness of design requirements, and to the extent provided for safeguards against unanticipated failure mode(s). This ranking has been defined by a range from "(A) Superior" to "(D) Poor" that is shown in Ref. [10] tables. Regarding the use of AASHTO LRFD for design of archetypes, there is a level of confidence in design specifications, but because of few experimental studies related to IAB's seismic behavior, $\beta_{D R}=0.2$ equivalent to (B) good quality has been chosen. 
3) Test Data Uncertainty (TD) is associated to the robustness and completeness of the data applied to identify the system and it can be quantitatively chosen from Ref. [10] tables. Considering the low experimental researches on connections, soil-pile-structure interaction and seismic loadings of IABs, $\beta_{T D}=0.5$ equivalent to (D) poor quality has been selected for this parameter.

4) Modeling Uncertainty (MDL) is associated to how properly index archetype models show the full range of structural response features and to the associated design parameters of archetype design space and how properly the analysis model(s) captures the structural collapse behavior by non-simulated or direct simulation of component checks. Bridges have been modeled in one or two spans (wall and stub type abutment) 10, 20 and 30 meter spans and two types of loose and dense soil. Thus, soil-pile-structure interaction has been taken into account beside nonlinear modeling of piles using fiber elements, however, with regarding 2D modeling and ignoring material deterioration. $\beta_{M D L}=0.2$ equivalent to $(\mathrm{B})$ good quality has been chosen for this parameter.

Total system collapse uncertainty is calculated as:

$$
\beta_{T O T}=\sqrt{\beta_{R T R}^{2}+\beta_{D R}^{2}+\beta_{T D}^{2}+\beta_{M D L}^{2}}=0.65
$$

\section{Results and discussions}

In this chapter, results are evaluated and discussed. As mentioned in section 5.9, ACMR average values for every performance group and $A C M R$ values for individual index archetype should be above the acceptable limit. Here, the results in terms of all archetypes as one performance group are discussed, then breaking up the archetypes based on some specific characters into some new performance groups are examined.

If all archetypes are put into one performance group, then $\overline{A C M R}_{i}=2.61$ which is above $A C M R_{10 \%}=2.30$. $A C M R_{i}$ for all archetypes is above $A C M R_{20 \%}=1.73$, except W30L2 that has an $A C M R$ value of 1.64 that is below the acceptable value. This means that $\mathrm{R}$ factor of 3.5 is suitable for IABs in the longitudinal direction with a marginal error.

Another approach in evaluation of $A C M R$ is making performance groups as shown in Fig. 10. Accordingly, all performance groups have average $A C M R$ above the allowable $A C M R$ based on $20 \%$ collapse probability, except the performance group of IABs with wall type abutment ( $7 \mathrm{~m}$ height). This observation shows that the $A C M R$ of all performance groups are only slightly higher than the acceptable $A C M R$, except for wall type abutment bridges, then it could be concluded that 3.5 could be a good and optimized response modification factor for IABs in the longitudinal direction.
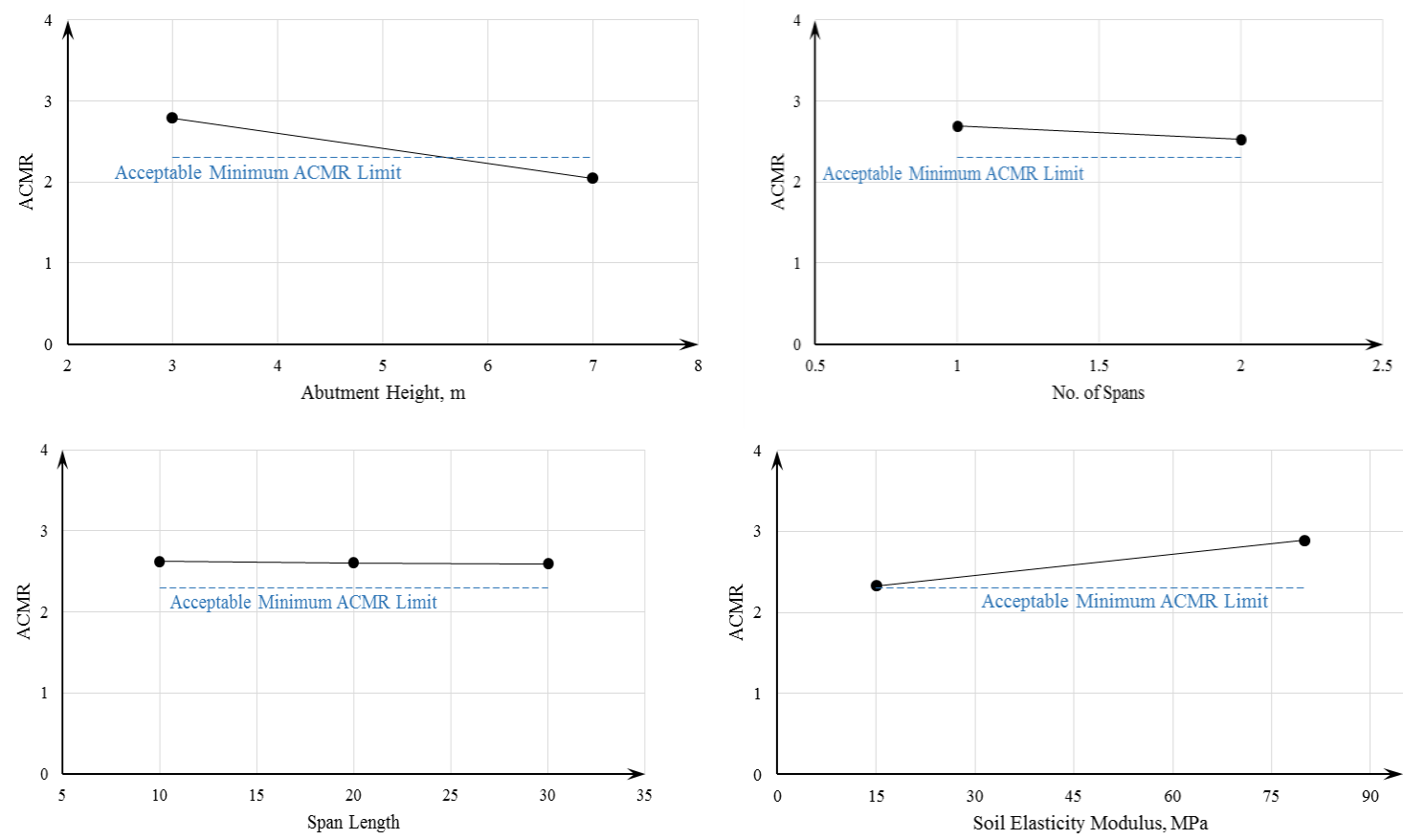

Fig. 10. The $A C M R$ of performance groups compared to the acceptable minimum $A C M R$ limit. (a) performance groups separated based on abutment height (b) performance groups separated based on number of spans (c) performance groups separated based on span length (d) performance groups separated based on soil elasticity modulus 
Another approach in evaluation of $A C M R$ is making performance groups as shown in Fig. 11. Thus, all performance groups have an average $A C M R$ above the allowable $A C M R$ based on $20 \%$ collapse probability, except the performance group of IABs with wall type abutment with height of 7 meters with either loose or dense soil type and any number of spans.

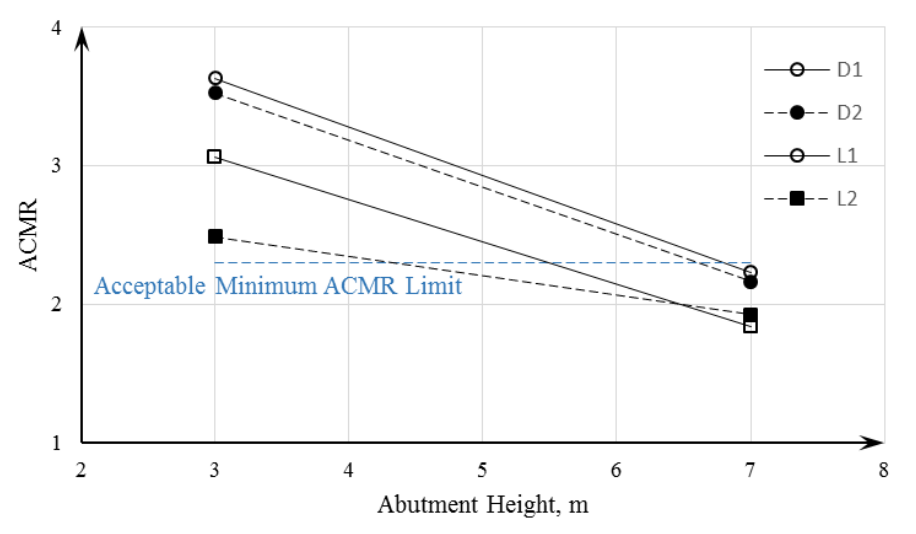

Fig. 11. values of $A C M R$ vs. Abutment height considering performance groups separated based on soil type, no. of spans and abutment height

As a result, the response modification factor 3.5 is acceptable for IABs in the longitudinal direction for all archetypes considered with the following reservations:

1) IABs with an abutment height more than 6.5 meters with dense soil behind abutment.

2) IABs with an abutment height more than 5 meters with loose soil behind abutment.

From the results, it is observed that:

1) The collapse capacity of IABs with stub type abutment is $55 \%$ more than the IABs with wall type abutments.

2) The collapse capacity of IABs with dense soil behind abutment is $24 \%$ more than those with loose soil behind abutment.

3) The collapse capacity of single span IABs is more than multiple span IABs.

4) The collapse capacity of IABs with 10 meters span is $0.8 \%$ more than the IABs with 20 meters span, and the collapse capacity of IABs with 20 meters span is $0.4 \%$ more than the IABs with 30 meters span.

From the observations mentioned above, it is seen that the height of abutment is the most important factor in the collapse capacity of IABs. The second most important parameter is the type of soil behind abutments. The least effective parameter in the collapse capacity of IABs is the number of spans and span length.

\section{Conclusions}

Based on the extensive analyses prescribed in FEMA P695 [10] the R factor in the longitudinal direction of common non-skewed IABs were determined. It was concluded that the response modification factor $\mathrm{R}=3.5$ is appropriate for design purposes. However, for IABs with abutment height above $6.5 \mathrm{~m}$ with dense backfill this value can be unsafe.

It is recommended by the authors that for IABs in seismic regions designers should avoid using loose soils behind abutments. Loose soils cause the collapse capacity of IABs to decline, especially those having abutment wall heights above 5 meters. Otherwise, in such cases, a lower response modification factor should be utilized.

It was also observed that stub type abutments had a better seismic performance than wall type abutments.

It was shown that the seismic performance of IABs were less sensitive to the number and length of spans within the range considered.

\section{References}

[1] Burke Jr MP. Integral and semi-integral bridges. 1st ed. John Wiley \& Sons; 2009.

[2] Erhan S, Dicleli M. Effect of dynamic soil-bridge interaction modeling assumptions on the calculated seismic response of integral bridges. Soil Dyn Earthq Eng. 2014;66:42-55. doi:10.1016/j.soildyn.2014.06.033.

[3] Civjan S, Bonczar C, Brena S. Integral abutment bridge behavior: Parametric analysis of a Massachusetts bridge. Journal of Bridge Engineering. 2007;12:64-71. doi:10.1061/(ASCE)1084-0702(2007)12:1(64).

[4] Spyrakos C, Loannidis G., Seismic behavior of a post-tensioned integral bridge including soil-structure interaction (SSI). Soil Dyn Earthq Eng. 2003;23:53-63. doi:10.1016/S0267-7261(02)00150-1. 
[5] Itani AM, Pekcan G. Seismic performance of steel plate girder bridges with integral abutments. 2011.

[6] Maleki S, Mahjoubi S. A new approach for estimating the seismic soil pressure on retaining walls. Sci. Iran. Trans. Civ. Eng. 2010;17(4): 273-284.

[7] Mahjoubi S, Maleki S. Finite element modelling and seismic behaviour of integral abutment bridges considering soil-structure interaction. Eur J Environ Civ Eng. 2020;24(6):767-786.

[8] Burdette EG, Ingram EE, Tidwell, JB, Goodpasture DW, Deatherage JH, Howard SC. Behavior of integral abutments supported by steel H-piles. Transportation Research Record. 2004. https://doi.org/10.3141/189203.

[9] AASHTO (American Association of State Highway and Transportation Officials). LRFD bridge design specifications. $8^{\text {th }}$ Edition. Washington DC, U.S.A. 2017.

[10] FEMA P695, Quantification of building seismic performance factors. Federal Emergency Management Agency, Washington DC, U.S.A. June 2009.

[11] Computers and Structures, Inc. SAP2000, Version 20, Integrated Structural Analysis and Design Software. Berkeley, CA, 2018.

[12] Faraji S, Ting JM, Crovo DS, Ernst H. Nonlinear analysis of integral bridges: Finite-element model. J Geotech Geoenvironmental Eng. 2001;127:454-461.

[13] Richards R. Huang C, Fishman KL. Seismic earth pressure on retaining structures. J Geotech Geoenv Eng. 1999;125:771-778.

[14] American Petroleum Institute (API). Recommended practice for planning, designing and constructing fixed offshore platforms-working stress design. 1st edition. API Recommended Practice 2A-WSD(RP2A-WSD). Dallas. 1993.

[15] Seismic evaluation and retrofit of existing buildings(ASCE/SEI 41-13). American Society of Civil Engineers(ASCE). 2013.

[16] Baker JW, Cornell CA. A vector-valued ground motion intensity measure consisting of spectral acceleration and epsilon. Earthq Eng Struct Dyn. 2005:1193-1217. doi:10.1002/eqe.474.

(C) 2021 by the author(s). This work is licensed under a Creative Commons Attribution 4.0 International License (http://creativecommons.org/licenses/by/4.0/). Authors retain copyright of their work, with first publication rights granted to Tech Reviews Ltd. 